\title{
Culture and grammar in scientific English
}

\section{Thomas Miller}

\section{(2) OpenEdition \\ Journals}

Electronic version

URL: http://journals.openedition.org/asp/4013

DOI: $10.4000 /$ asp.4013

ISSN: 2108-6354

\section{Publisher}

Groupe d'étude et de recherche en anglais de spécialité

\section{Printed version}

Date of publication: 1 December 1994

Number of pages: 31-44

ISSN: $1246-8185$

\section{Electronic reference}

Thomas Miller, «Culture and grammar in scientific English », ASp [Online], 5-6 | 1994, Online since 28 November 2013, connection on 02 May 2019. URL : http://journals.openedition.org/asp/4013 ; DOI : 10.4000/asp.4013

This text was automatically generated on 2 May 2019.

Tous droits réservés 


\title{
Culture and grammar in scientific English
}

\author{
Thomas Miller
}

J.R. Martin (1992) shows how various levels in meaning constrict our choices in those below (see fig. 1).

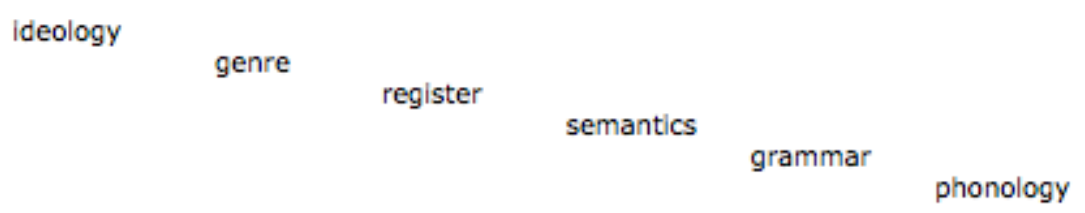

2 In this paper we will concentrate on the relations between ideology, genre, register and grammar. Martin (1985) explains that genres are how things get done when language is involved. Genres 'range from literary to far from literary forms: poems, narratives, expositions, lectures, seminars, recipes, manuals, appointment making, service encounter, news broadcasts and so on'. Register is defined as "the configuration of semantic resources that the member of a culture associates with a situation type. It is the meaning potential that is accessible in a given social context" (Halliday 1978: 111). Halliday calls register the context's expression plane. Register consists of:

field - the social action, 'What is actually taking place?'

tenor - the role structure, 'Who is taking part?'

mode - the symbolic organization 'What role is language playing in the situation?'

(Martin 1992: 500)

Register changes are motivated by genre. A teacher may change fields to explain a point by analogy, a beggar may change tenor and become threatening to reach his/her goal, or a coach unable to explain a certain technique may shift modes and demonstrate rather than speak. Certain genres are associated with certain activities. Few people lecture about typing, bicycle maintenance or house cleaning although there is no reason why they couldn't. But these fields simply do not combine with the power (tenor) and abstract reflective monologue (mode) in our culture. When people are being socialized into these institutions, genres other than lectures are used. 
Based on the context or register, the speaker/writer must make many linguistic choices. Speaking to a superior (tenor) demands quite different linguistic choices at the interpersonal linguistic level. It is unusual to command up the hierarchy (although my children, who haven't yet figured out that I in theory at least occupy a power position, do not follow this precept). The field determines to a great extent which terms and, as we will see, structures we use at the ideational level. Finally, the mode to a great extent shapes how the language is packaged at the textual level. A telephone conversation, for example, must rely more on language as a resource and less on visual resources such as gestures or exophoric reference in contrast to a conversation face-à-face:

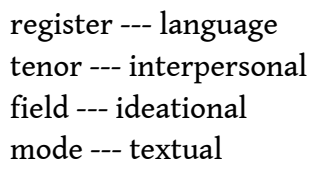

5 To see the relationship between levels, let us look at how decisions made at the ideology level determine those at the genre and register level for the scientist. Later we will spend most of the paper looking at how all of these choices are reflected at the grammatical level.

\section{Ideology of the Scientist}

6 In academic culture we are taught to be objective, to let nature speak for itself (Bazerman). Science increasingly is theory driven. Facts of the world have little interest in themselves in the world of the scientist unless they can fit into a more general theory. Those facts which do not conform to an accepted theory can cause a paradigm shift (Kuhn) as a new theory takes the place of the old -a scientific revolution as it were. It is very important for the scientist that his/her data be replicable. The patterns of reduplication allow a new piece of information to become scientific 'fact'. ${ }^{1}$ One of the best ways of making data replicable is to measure, count and compare phenomena carefully. The scientist must be objective, separating in some way the observer from the observed. In fact, there is a special word, 'the Hawthorne effect', for cases where the very act of observing a phenomenon changes it. Knowledge is built up in increments, and a contributor to the field must demonstrate that he or she knows the issues and can add a new piece of knowledge.

\section{Genre - the Research Paper}

One of the main vehicles for disseminating information for building knowledge is the research paper. To reach publication, the writer shows in his/her introduction that she has a grasp of the subject matter but has found a gap in the knowledge (Swales 1990), justifying yet another paper. The methods section in the experimental paper allows for reduplication, while the discussion sections may refer back to the theory or point out future areas of research. The writer of the research paper must know which journal publishes what kind of article and in order to keep up with developments in the field must have mastered a host of cultural and interpersonal skills associated with attending conferences, writing for advance copies of papers, passing the paper to colleagues for suggestions, working with a team on the research, etc. Thus the research paper is just the tip of the iceberg in terms of activities involved in producing it. 


\section{Register - Peer to Peer}

Because every new contribution to science threatens someone else's theory, the scientist must buttress his or her thesis with mountains of data. One cannot make too strong a claim, because the potential hostile reader may have a competing claim or may have considered factors ignored in the original paper. Every former researcher quoted or omitted opens the writer up for attack. In fact many academics go first to the bibliography to decide whether the article is worth reading.

\section{Language - A reflection of ideology and register}

In order to demonstrate how loaded scientific articles are with culture, we will compare two articles which more or less hold field constant - an article from the January 31 issue of Newsweek introducing new plate tectonics to the general reader with one of the classic articles from the Journal of Geophysical Research, which first introduced new plate tectonics to the discourse community of geophysicists. Since the article from the Journal of Geophysical Research, was 41 pages long, we will include only those sections which explain the same phenomena as the first page of the Newsweek article. Notice how the title and first two sentences of each genre situate the rest of the text (see table 1).

Table 1

\begin{tabular}{|c|c|}
\hline Newsweek (NW) & Journal of Geophysical Research (JGR) \\
\hline title & title \\
\hline A WHOLE LOT OF SHAKIN' Goin' & Seismology and the New Global \\
\hline ON & Tectonics \\
\hline $\begin{array}{l}\text { 1. ONCE AGAIN, IT WAS A FAULT } \\
\text { THEY couldn't see that slammed Los } \\
\text { Angelenos, crumpled their freeways } \\
\text { and toppled their buildings like } \\
\text { Tinkertoys. } \\
\text { 2. Although the San Andreas fault gets } \\
\text { all the notoriety, geophysicists are } \\
\text { now realizing that dozens of invisible, } \\
\text { even unsuspected fractures in the } \\
\text { rocks beneath the Los Angeles basin } \\
\text { cause more of the earthquakes, large } \\
\text { and small. }\end{array}$ & $\begin{array}{l}\text { 1. This paper relates observations from the filed of } \\
\text { seismology and allied disciplines to what is here } \\
\text { termed the 'new global tectonics.' } \\
\text { 2. This term is used to refer in a general way to current } \\
\text { concepts of large-scale tectonic movements and } \\
\text { processes within the earth, concepts that are based on } \\
\text { the hypotheses of continental drift (Wegner, 1966), } \\
\text { sea-floor spreading (Hess, 1962: Dietz, 1961), and } \\
\text { transform faults (Wilson, 1965c) and that include } \\
\text { various refinements and developments of these ideas. }\end{array}$ \\
\hline
\end{tabular}

10 The informal, unguarded, conversational and song-title nature of the Newsweek title indicate to the reader that American popular culture will be the reference point for the article. All the words in the first line are in caps, which turns the volume up and gets our attention as does the use of italics to highlight 'couldn't see. The article is situated (what 
Martin 1993, calls hypertheme) from the perspective of one event. The earthquake is an actor slamming, crumpling and toppling people and infrastructure. The analogy 'like Tinkertoys' leaves the field of geology and enters the realm of the home full of children's toys, creating a vivid image of small buildings facing a huge force. All of these factors create a feeling of involvement (Tannen 1989) and familiarity between writer and audience.

11 The geophysics article is very different. From the first sentence we can see that the article will be about hypotheses, observations, concepts and ideas. The article promises to link various disciplines to create a new specialty 'new global tectonics'. The intertextuality of researchers receives great prominence as study after study is cited. This situates the article within the scientific community in contrast to the Newsweek article, which situates the text from the perspective of an individual event and within our homes and daily lives.

There is a certain iconicity between promotion within the noun phrase and importance given to a concept within the discourse community (see fig. 2).

Figure 2

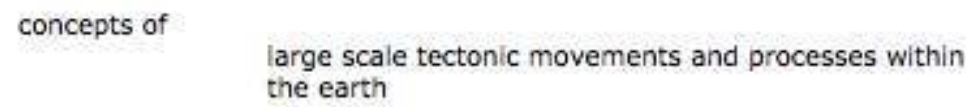

13 The macro theme (Halliday \& Martin 1992) of the paper includes concepts as grammatical heads. The actual movement of the earth, the 'continental drift' is included within a prepositional phrase which is modifying a noun which is part of a complement within a relative clause! In contrast to the Newsweek article, the ideas dominate grammatically and the earthly happenings are demoted throughout.

14 It is interesting, then, to view to role that the visuals play in the respective articles. The geophysics article makes constant reference to the graphs. One cannot even understand sentences 15,17 and 19 without them (see appendix):

15. In this hypothesis the active portion (BC in Figure 30-4) of a strike-slip fault along which large horizontal displacement ...

15 Only one sentence (20) in the Newsweek article even refers to the diagram but as an aside: (diagram):

19. They angle up like a ramp (diagram).

16 The diagrams in the Newsweek article provide visualization for individual events or places of the events. The diagrams in the geophysics article, on the other hand, are visualizations of the theories which are elaborated in the text. The visuals in the geophysics article function much as macrothemes, dominating large stretches of texts, while those in the Newsweek article act much as individual pieces of news. The visualization of the theories in the geophysics article reflects the saliency of the theory, which has in a way become concretized. Let us compare briefly how the two genres introduce the hypothesis of new plate tectonics:

Newsweek 
6. In the reigning theory of geology, the earth is likened to a chocolate-covered cherry that's been roughed up. 7. The crust - the chocolate shell - has been smashed into seven big chunks called tectonic plates. 8. The plates float over the molten magma (the gooey syrup), slipping and sliding laterally along each other's edge. 9. But the jagged, rocky plates do not slide past each other smoothly. 10. They stick. up'. One leaves the field of geophysics altogether to the world of candy which is personified by being 'roughed up'. In the geophysics article the analogy remains in the field of geophysics. One is still speaking of 'surface patterns' and 'patterns of convection'. Notice too how even in the extended analogy the process has been frozen (here quite literally!) so that it can be compared, counted and measured.

Let us analyze sentence 5 in the geophysics article for a moment as an example how the genre tilts the grammar towards the dominating ideology (see fig. 3).

\section{Figure 3}

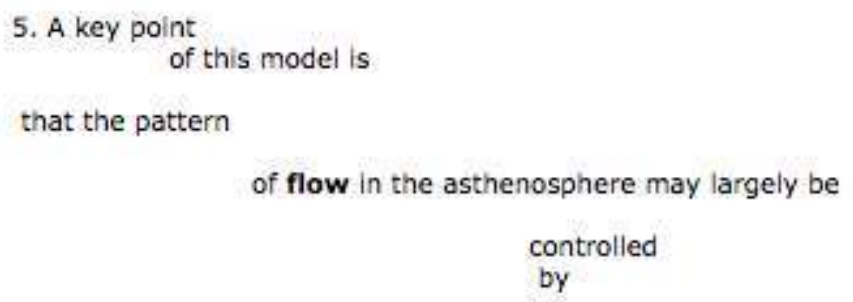



old theory is challenged. The scientist's interest in patterns causes him to promote pattern to the head noun. The choice of the word pattern implies observations over time or comparison of data with peers. The physical actors in the process i.e. the earth in the last noun phrase has been demoted five times. The main verb of the sentence is turns the action of flowing into the bleached out a static relation and suggests that we are not really interested in cause and effect but in patterns. Notice also how all of the process highlighted (flow, motions, fit) have been nominalized or frozen in time so that they could be treated as objects.

In a wonderful book entitled Writing Science, Martin and Halliday (1993: 218) suggest that we learn more 'congruent' structures first and acquire 'metaphorical' uses of grammar later. In the most congruent use of the language, processes are coded as verbs, qualities as adjectives and logical relations as conjunctions (see table 2).

Table 2

\begin{tabular}{|l|l|}
\hline semantics & grammar \\
\hline participant & noun \\
\hline process & verb \\
\hline quality & adjective \\
\hline logical relation & conjunction \\
\hline assessment & modal verb \\
\hline
\end{tabular}

Martin and Halliday call the process of packaging a text in a non-conventional way 'grammatical metaphor'.

One can see that in the research article many of the relationships between participants in the clause (even a lot of cause and effect) are presumed and thus embedded within prepositional phrases within other groups of the clause. Rarely do we find congruent uses of conjunctions such as 'because'. For example, even though sentences 6 and 7 are within the section of the paper asserting the new theory, they code complex series of causes and effects largely within noun phrases (see fig. 4).

Figure 4

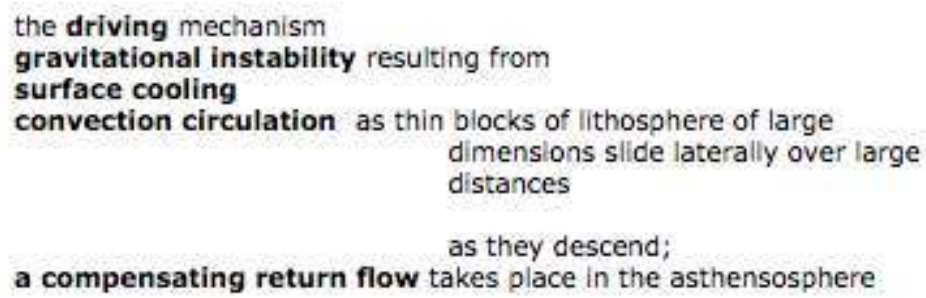

The words in bold are all used in a metaphorical sense. One could state in a more congruent fashion that 'A happens because of B' or perhaps somewhat less congruently 'A 
causes B'; surface cooling could be coded as 'It becomes cool on the surface'. A compensating return flow would need to be coded as, 'The blocks flow back to compensate for the gap...' Notice that in this type of nominalization much information such as logical relations is lost as the prepositions qualifying nouns or even the cause words themselves are lost. I would rephrase sentence 6 more congruently as 'Because the surface cools, it becomes more dense, which causes the surface to become unstable, which...', but this makes it very difficult to clearly show the relationship between the ideas. Experts in the field would not need these extra function words since their superior knowledge of the field allow them to fill in the gaps.

The ideational portion of the original sentence (we will discuss the interpersonal theme later) promotes basic driving mechanism to head of the noun phrase, telling the reader that the sentence will deal largely with cause and effect with gravitational instability the most important cause. My more congruent version with the additive clauses makes it difficult to create a hierarchy of ideas. Without grammatical metaphor - changing a process to a thing - it would be very difficult to describe, measure, and compare processes. Grammatical metaphor allows the author to highlight those ideas which are key to the argument and demote those which are less salient.

Grammatical metaphor also allows the writer to thematize elements as the launching points of discussion. According to Martin:

Theme in a sense provides the text's angle on its field; it is the peg or two on which the rest of the text's meanings are hung. New by contrast elaborates the field, developing its meaning -fleshing out the construction of experience with which the text is concerned. Looking upwards to context, Theme is genre oriented, angling a text in relation to its social purpose; New on the other hand focuses on field, developing the institution at hand. (1992, p. 244) In our academic text data, models, mechanisms and hypotheses form the ideational theme in half of the sentences in the scientific article (Table 3)

Table 3

\begin{tabular}{|l|l|}
\hline interpersonal & textual ideational \\
\hline 1. & This paper \\
\hline 2. & This term \\
\hline 3. & $\begin{array}{l}\text { The counter flow corresponding to movement of the lithosphere into the upper } \\
\text { mantle }\end{array}$ \\
\hline 4. & To what extent \\
\hline 5. & A key point of this model \\
\hline 6. & tempting to think that the basic driving mechanism for this process \\
\hline 7. & Thus convective circulation in the upper mantel \\
\hline 8. & The process ${ }^{2}$ in the real earth \\
\hline
\end{tabular}




\begin{tabular}{|c|c|}
\hline 9. & $\begin{array}{l}\text { Where one block of the lithosphere is moving past another along the surface at } \\
\text { the zones of large strike-slip faulting }\end{array}$ \\
\hline 10. & Some zones \\
\hline 11. & The general pattern of earthquake focal mechanisms \\
\hline 12. & The depth of the deepest earthquakes \\
\hline 13. & The mobile lithosphere hypothesis \\
\hline 14. & Although the concept of....area \\
\hline 15. & In this Earthquake mechanisms from this region \\
\hline 16. & The horizontal displacement \\
\hline 17. & Two separate segments of the ridge crest \\
\hline 18. & These faults \\
\hline 19. & $\mathrm{He}$ \\
\hline 20. & If the crestal zones ....offset \\
\hline 21. & A similar pattern en echelon ridges \\
\hline 22. & Earthquake mechanisms from this region \\
\hline 23. & These transform faults \\
\hline 24. & Hence sea floor spreading and transform faulting \\
\hline 25. & Critical evaluation of focal mechanism data \\
\hline 26. & The recent data, greatly improved ...quality \\
\hline 27. & $\begin{array}{l}\text { The thrust fault mechanism characteristic of shallow earthquakes in island } \\
\text { arcs }\end{array}$ \\
\hline 28. & $\begin{array}{l}\text { The compatibility of these motions as determined by focal mechanism data } \\
\text { with the worldwide pattern of plate movement }\end{array}$ \\
\hline 29. & Considerable evidence for underthrusting in the main shallow seismic zone \\
\hline 30. & $\begin{array}{l}\text { Geodetic and geologic studies of the Alaskan earthquake of } 1964 \text { (Parkin, 1966; } \\
\text { Plafker, 1965) }\end{array}$ \\
\hline 31. & Geologic evidence \\
\hline 32. & $\begin{array}{l}\text { Data from other arcs on crustal movements from other arcs on crustal } \\
\text { movements }\end{array}$ \\
\hline
\end{tabular}




\begin{tabular}{|l|l|}
\hline 33. & In fact in many areas \\
\hline 34. & One important point ${ }^{3}$ \\
\hline 35. & well known (Richter, 1958) that vertical movements \\
\hline 36. & This \\
\hline
\end{tabular}

31 If field can be contrasted to genre as suggested by Martin, the themes highlighted suggest the ideology of the discourse community of scientists looking for data to bolster or challenge their theories. Nominalization allows the writer to describe many elements in one clause. In sentence 28 , for example, the head noun compatibility, suggests a testing of a hypothesis, which in the same theme include the words: mechanism, data and pattern. Thus in one noun phrase the author suggests he is comparing and testing (compatibility) data, looking at patterns in order to determine the cause (mechanism) of observed data. Nominalization also allows the author to place interpersonal words within the ideational theme: considerable evidence', highlighting the importance of the evidence while staying in the ideational realm.

In the Newsweek article, on the other hand the themes all stay within the field of plate tectonics (see table 4).

Table 4

\begin{tabular}{|l|l|}
\hline interpersonal & textual ideational \\
\hline 1. & *Once again \\
\hline 2. & Although the San Andreas fault ...notoriety \\
\hline 3. & And that \\
\hline 4. & $\begin{array}{l}\text { Since these hidden faults do not have wires and meters attached to them like } \\
\text { an intensive-care patient, }\end{array}$ \\
\hline 5. & Worse if a quake jumped from fault to fault and ripped ... 100-mile fault zone" \\
\hline 6. & In the reigning theory of geology \\
\hline 7. & The crust - the chocolate shell - \\
\hline 8. & The plates \\
\hline 9. & But the jagged, rocky plates \\
\hline 10. & They \\
\hline 11. & When the rock can no longer withstand the stress, \\
\hline
\end{tabular}




\begin{tabular}{|c|c|}
\hline 13. & *Just east of L.A. \\
\hline 14. & *Here \\
\hline 15. & The battering \\
\hline 16. & (These faults \\
\hline 17. & In contrast, ${ }^{*}$ the San Andreas \\
\hline 18. & These buried thrust faults \\
\hline 19. & But they \\
\hline 20. & Instead, they \\
\hline 21. & $\begin{array}{l}\text { When the rocks can no longer withstand the terrific force of the ramming } \\
\text { Pacific plate, }\end{array}$ \\
\hline 22. & That \\
\hline 23. & *Nine miles underground \\
\hline 24. & The seismic wave \\
\hline 25. & $\mathrm{xxxx}^{4}$ \\
\hline 26. & But *since then \\
\hline 27. & Thrust faults \\
\hline 28. & This activity \\
\hline 29. & If they are \\
\hline
\end{tabular}

In contrast to the analogies, the themes of Newsweek article stay 'on field'. Seventeen of the 29 themes refer to faults, plates or seismic waves and only one to a theory. Six of the ideational themes contain references to specific places and times. In other words the real world of space and time is the jumping off point for many of the sentences.

Finally let us take a brief look at grammatical metaphor in the area of the main verb of the sentences in our respective genres. In the Newsweek article verbs are salient, active and even violent. The faults slam people, crumple freeways, and topple buildings. Quakes jump, rip zones while the earth's crust is smashed in chunks. Normally stative situations are turned into violent confrontations. The San Andreas pierces the ground hundreds of times (17) and the earth's crust is smashed in chunks (7). Nouns become verbs as 'faults angle up like ramps' (20). Here we can see that there is grammatical metaphor but in the direction of action and movement. In the Journal of Geophysical Research, this information is coded within such noun phrases as seismic activity. 
While the verbs in the Newsweek article form metaphors in the direction of salient action verbs, verbs in the Journal of Geophysical Research, are beached out. Let us look at the main verbs in the sentences as examples (see table 5).

Table 5

\begin{tabular}{|c|c|}
\hline Verb Type & Verb \\
\hline 1. (non state) activity & relates \\
\hline 2. (non state) activity & is used \\
\hline 3. (non state) goings on & takes place \\
\hline 4. (state) quality (attribute) & is \\
\hline 5. (state) identification & is \\
\hline 6. (state) identification) & is (gravitational ..) \\
\hline 7. (non state) goings on & occur \\
\hline 8. (state) quality (attributive) & be \\
\hline $\begin{array}{l}\text { 9. (state) quality (attributive) } \\
\text { (state) perception }\end{array}$ & $\begin{array}{l}\text { combine } \\
\text { are observed }\end{array}$ \\
\hline 10. (state) quality (attributive) & is \\
\hline $\begin{array}{l}\text { 11. (state) quality (attributive) } \\
\text { (non state) activity }\end{array}$ & 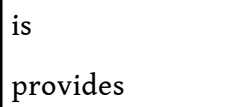 \\
\hline 12. (state) quality (attributive) & been \\
\hline 13. (non state) activity & offers \\
\hline 14. (state) intellect & assumes \\
\hline 15. (state) stance & ends \\
\hline 16. . (non state) transitional event & is transformed \\
\hline 17. (non state) activity & can be joined \\
\hline 18. (state) intellect & recognized \\
\hline 19. (non state) activity & pointed out \\
\hline 20. (state) temporary state & be (present) \\
\hline 21. (state) temporary state & is (present) \\
\hline
\end{tabular}




\begin{tabular}{|l|l|}
\hline 22. (state) quality (attributive) & are \\
\hline 23. (state) stance & arranged \\
\hline 24. (state) quality (attributive) & were responsible \\
\hline 25. (non state) activity & shows \\
\hline 26. (non state) activity & indicate \\
\hline 27. (state) attribute & reflect \\
\hline 29. (state) temporary state & exists \\
\hline 30. (non state) activity & support \\
\hline 31. (non state) activity & indicates \\
\hline 32. (state) quality (attributive) & are \\
\hline 33. (state?) stance? & outcrop \\
\hline 34. (non state) activity & be made \\
\hline 35. (state) quality (attributive) & are \\
\hline 36. (state) quality (attribute) & contrasts \\
\hline
\end{tabular}

It should not surprise us that the text is dominated by stative verbs. The text is in large describing phenomena and data. Even non-state verbs are become less salient such as occur or takes place. It is interesting to take a closer look at some of the activity verbs such as provides in 11, offers in 13 show in 25 and indicate in 26 and support in 30 . The subjects of these verbs are not human (at least not directly) but data in 11, hypothesis in 13, critical evaluation in 25 and data in 26 and studies in 30 respectively. Another example of an activity verbs - relates in 1 refers to the article. The action has moved towards science as hypotheses and data. The human element is implied indirectly as in critical evaluation. Let us look at all of sentence 11 to see how the words are functioning in context:

11. The general pattern of earthquake focal mechanisms is in remarkable agreement with the pattern predicted by the movements of the lithosphere determined in other ways and provides much additional information on this process.

Who is doing the predicting and determining? It is the scientist not nature. The scientists hide behind the surface grammar, making it appear as if nature is speaking for them.

The scientist uses many more synonyms when describing how nature relates to the data. Nature provides, shows and predicts. However, in the words on field the exact technical words rather than synonyms are provided. In the Newsweek article it is just the opposite. There is much use of synonyms but very little variation in the way nature is viewed. 


\section{Conclusion} We have seen how every element in the text from the size of the print, the integration of the visuals to the grammatical structures chosen reflects the ideology and context of the writer/reader. Genre is the plane which governs choices at the register level, which in turn influence choices in the language used..$^{5}$ One of the main tools at the writer's disposal is grammatical metaphor:

Somewhat iconically the, although science does concern itself with processes, analyzing them in explanations, in the end it interprets processes as things. Technical verbs are rare, and those that exist are seldom used. (Martin 1992: 212)

41 We saw from the Newsweek article that the ideology of the writer -to catch the interest of the reader and present a vivid picture- results in salient, action-filled verbs such as smashed and slammed. In the academic journal, the ideology of comparing, categorizing and measuring changes processes to nouns, leaving semantically empty relation verbs.

The authors of the earthquake article in Newsweek possess superior knowledge about plate tectonics vis-a-vis the putative ignorant reader. Because of the maximal distance, the authors try to become as close as possible to the reader through the use of oral strategies such as reduced word forms (shakin') and verbal underlining (couldn't see) or involvement strategies such as metaphor and similes. There is no qualification regarding theories of how nature functions nor any separation between observer and observed. One has a text in which the authors can write in an unguarded, informal fashion, not worrying about attacks from hostile readers.

43 In the academic text a more equal writer reader relationship prevails. Because the writers write for peers, whose theories may be threatened by the publication, texts must be buttressed by mountains of data. One could argue in fact that length of text itself is part of the interpersonal aspect of language. The more one is on the defensive the more one feels the need to explain. The distinction between observer and observed is maintained even if indirectly. Because of the equal power relationship between reader and writer, the writer maintains maximum distance between subject matter and self, often imputing challenges to present dogma to fellow researchers.

One can see then the importance of ideology and tenor in genre. The question thus arises, 'What is the use of providing technical articles in popular journals to students of ESP?'. A view of ESP which is field dominated would find no problem with this. However, the point of entry itself can cause other cultural problems: buildings are toppled like tinkertoys while the earth is compared to a chocolate-covered cherry. In some ways one has substituted one set of problems for another. If we wish to prepare our students to enter the discourse community of scientists, they need exposure to texts impregnated with the ideology and culture expressed in the genre and not just the technical terms and phenomena depicted in the field. If we help our students become aware of the hidden cultural messages contained in all texts, they will better understand the real message of the text and may in turn become participants in the 'field' themselves. 


\section{BIBLIOGRAPHY}

Halliday, M.A.K. 1978. Language as Social Semiotic. London: Edward Arnold.

Halliday, M.A.K. and J.R. Martin. 1993. Writing Science. London: Falmer Press.

Martin, J.R. 1985. Actual Writing: Exploring and challenging social reality. Geelong, Vic.: Deakin

University Press.

Martin, J.R. 1992. English Text: System and Structure. Philadelphia/Amsterdam: John Benjamins.

Swales, J. 1990. Genre Analysis: English in academic and research settings. Cambridge: Cambridge

University Press.

Tannen, Deborah. 1989. Talking Voices: Repetition, Dialogue, and Imagery in Conversational Discourse.

Cambridge: Cambridge University Press.

\section{APPENDIXES}

\section{Appendix 1: Extracts from the Newsweek article}

\section{A WHOLE LOT OF SHAKIN' GOIN' ON (1994)}

1. Once again, it was a fault they couldn't see that slammed Los Angelenos, crumpled their freeways and toppled their buildings like Tinkertoys. 2. Although the San Andreas fault gets all the notoriety, geophysicists are now realizing that dozens of invisible, even unsuspected, fractures in the rocks beneath the Los Angeles basin cause most of the earthquakes, large and small. 3. And that has radically changed the seismic calculus. 4. Since these hidden faults do not have wires and meters attached to them like an intensive-care patient, scientists will not get any tip-off that a big trembler is coming - as they hope to if, say, the heavily instrumented San Andreas gives way. 5. Worse, "if a quake jumped from fault to fault and ripped the full 100-mile fault zone," says seismologist Tom Henyey of the Southern California Earthquake Center, "there could be an earthquake that registers close to an 8 " on the Richter scale - about 125 times more powerful than last week's jolt.

6. In the reigning theory of geology, the earth is likened to a chocolate-covered cherry that's been roughed up. 7. The crust - the chocolate shell - has been smashed into seven big chunks called tectonic plates. 8 . The plates float over the molten magma (the gooey syrup), slipping and sliding laterally along each other's edge. 9. But the jagged, rocky plates do not slide past each other smoothly. 10. They stick. 11. When the rock can no longer withstand the stress, the plates surge past each other with all of the accumulated strain - an earthquake. 12. It turns out, however, that faults lie not only at the junctures of plates but within them as well. 13. Just east of L.A., the San Andreas fault, which separates the Pacific and North American plates and usually runs north-south, turns abruptly west (map). 14. Here, the Pacific plate, drifting northwest, rams the North American. 15. The battering shatters the continent's crust, creating a web of "blind thrust faults" that resembles a windshield after a car crash. 16. (These faults are "blind" because 
they do not break the surface and so are unseen. 17. In contrast, the San Andreas pierces the ground hundreds of times.) 18. These buried thrust faults, which scientists began to take seriously as quake hazards in the 1980s, run horizontally, dividing a plate into a top and bottom. 19. But they are not perfectly flat. 20. Instead, they angle up like a ramp (diagram). 21. When the rocks can no longer withstand the terrific force of the ramming Pacific plate, the top chunk of real estate surges over the slab below.

22. That's what happened in Northridge. 23. Nine miles underground, one of the thrust faults - the culprit hasn't been identified yet -gave way. 24. The seismic wave traveled outward at two or three miles per second along the tilted fault line, but never broke the surface. 25. There's this whole seismic hazard from buried thrust faults that we didn't even appreciate until six years ago," says seismologist James Dolan of the California Institute of Technology in Pasadena. 26. But since then southern California has been shaken by seven thrust-fault quakes registering 4.5 or above. 27. Thrust faults also lie under the Alps and the Himalayas.

28. This activity has forced researchers to consider a horrendous possibility: that the hidden thrust faults are connected deep underground.

\section{Appendix 2: Extracts from the Journal of Geophysical Research article}

\section{SEISMOLOGY AND THE NEW GLOBAL TECTONICS by BRYAN ISACKS, JACK OLIVER, LYNN R. SYKES (1968)}

p. 3581 . This paper relates observations from the field of seismology and allied disciplines to what is here termed the 'new global tectonics.' 2. This term is used to refer in a general way to current concepts of large-scale tectonic movements and processes within the earth, concepts that are based on the hypotheses of continental drift (Wegener, 1966), sea-floor spreading (Hess, 1962; Dietz, 1961), and transform faults (Wilson, 1965c) and that include various refinements and developments of these ideas.

p. 360 3. The counterflow corresponding to movement of the lithosphere into the deeper mantle takes place in the asthenosphere, as indicated schematically by the appropriate arrows in the figure. 4 . To what extent, if any, there is flow of the adjoining upper part of the asthenosphere in the same direction as the overlying lithosphere is an important but open question, partially dependent on the definition of the boundary. 5. A key point of this model is that the pattern of flow in the asthenosphere may largely be controlled by the configurations and motions of the surface plates of lithosphere and not by a geometrical fit on convection cells of simple shape into an idealized model of the earth. 6 . It is tempting to think that the basic driving mechanisms for this process is gravitational instability resulting from surface cooling and hence a relatively high density of nearsurface mantle materials. 7 . Thus, convective circulation in the upper mantle might occur as thin blocks of lithosphere of large horizontal dimensions slide laterally over large distances as they descend; a compensating return flow takes place in the asthenosphere. 8. The process in the real earth must be more complex than this simple model, however.

p. 362 9. Where one block of the lithosphere is moving past another along the surface at the zones of large strike-slip faulting, seismic activity is shallow, but occasional rather large shallow earthquakes are observed. 10. Some zones combine thrusting and strike-slip motion. 11. The general pattern of earthquake focal mechanisms is in remarkable agreement with the pattern predicted by the movements of the lithosphere determined in other ways and provides much additional information on this process. 12. The depth of 
the deepest earthquake (about $700 \mathrm{~km}$ ) has been reasonably well known, but unexplained, for many years. 13. The mobile lithosphere hypothesis offers, at this writing, several possible alternatives to explain this observation.

p. 36314 . Although the concept of simple offset tacitly assumes the conservation of surface area, the growth or the destruction of surface area is basic to the definition of the transform fault. 15. In this hypothesis the active portion (BC in Figure 30-4) of a strikeslip fault along which large horizontal displacement has occurred ends abruptly at the crest of a growing ocean ridge. 16 . The horizontal displacement along the fault is transformed (or absorbed) by sea-floor growth on the ridge; the growing ridge is, in turn, terminated by the fault. 17. Two separate segments of ridge crest can be joined (Figure 30-4) by a strike-slip fault of this type; these faults are called transform faults of the ridge-ridge type.

18. Wilson (1966c) recognized that the sense of shear displacement along transform faults of the ridge-ridge type would be exactly opposite that required for a simple offset of the two segments of ridge crest. 19. He also pointed out that seismic activity along transform faults should be confined to the region between the two ridge crests (segment $\mathrm{BC}$ in Figure 30-4). 20. If the crestal zones are being displaced by simple offset, however, seismic activity should be present along the entire length of the fracture zone.

p. 369 21. A similar pattern of en echelon ridges is present in the Gulf of California (Figure 30-6). 22. Earthquake mechanisms from this region are indicative of a series of northwesterly striking transform faults with right-lateral displacement (Sykes, 1968). 23. These transform faults, which are arranged en echelon to the San Andreas fault, connect individual segments of growing ridges in the Gulf of California. 24. Hence, sea-floor spreading and transform faulting also were responsible for the displacement of Baja California relative to the mainland of Mexico.

p. 373 25. Critical evaluation of focal mechanism data by Adams (1963), Hodgson and Stevens (1964), Stauder (1964), and Ritsema (1964) shows that the generalization that strike-slip faulting is predominant in island arcs is based on unreliable data and possible systematic errors in the analyses. 26 . The recent date, greatly improved in quality and quantity, indicate that, in fact, dip-slip mechanisms are predominant in island arcs. 27. The thrust fault mechanisms characteristic of shallow earthquakes in island arcs thus appear to reflect directly the relative movements of the converging plates of lithosphere and the downward motion of the oceanic plate. 28. The compatibility of these motions as determined by focal mechanism date with the worldwide pattern of place movements is discussed later and is shown to be excellent. 29. Considerable evidence for underthrusting in the main shallow seismic zone exists in other kinds of observations. 30. Geodetic and geologic studies of the Alaskan earthquake of 1964 (Parkin, 1966; Plafker, 1965) strongly support the concept of underthrusting. 31. Geodetic evidence also indicates the repeated occurrence of such thrusting in this arc during recent time (Plafker and Rubin, 1967). 32. Data from other arcs on crustal movements are voluminous and have not all been examined in light of the hypotheses of the new global tectonics. 33. In fact, in many arcs the principal zone of underthrusting would outcrop beneath the sea and important data would be largely obscured. 34 . One important point can be made. 35. It is well known (Richter, 1958) that vertical movements in island arcs are of primary importance. 36. This contrasts with the predominantly horizontal movement in such zones as California, 
where strike-slip faulting predominates. Journal of Geophysical Research, 73, 1968, pp. 5855-5899.

\section{NOTES}

1. We saw in the case of cool fusion how a scientist's reputation can suffer is his or her data cannot be duplicated.

2. Since process is comparing the earth to the model, one could conceivably count this as well.

3. In this sentence as well as in sentence 5 the empty noun 'point' provides a peg for the interpersonal adjective which gives the writer's point of view. In the present analysis, it appears as if there is no ideational theme. Thus the whole sentence could be considered a launching point for sentence 34 .

4. 'There' could be considered theme introducing.

5. Although this paper has studied one text of one genre, the different lessons drawn from various genres would still validate the conclusions drawn here.

\section{ABSTRACTS}

This paper tries to answer the question of how culture manifests itself in the grammar of the language. To do so, two articles from the same field, i.e., with identical subject matter but from different genres, are examined. Culture depends not only on the subject matter, as is generally acknowledged, but also depends on the relationship between the speaker/writer and listener/ reader. The reason so many people say there is no culture in ESP is that they are focusing on the field rather than on the genre. We look at these issues largely from the perspective of systemic grammar.

Dans cet article, on essaie de répondre à la question de savoir comment la culture se manifeste à travers la grammaire de la langue. Pour ce faire, deux articles du même domaine (c'est-à-dire traitant d'un même sujet, mais appartenant à deux genres différents) sont étudiés. L'élément culturel n'est pas seulement dépendant du sujet traité; il ressortit aussi à la relation auteur/ lecteur. Si tant de gens prétendent qu'il n'y a pas de culture dans la langue de spécialité, c'est qu'ils ne voient que le domaine, au lieu de s'intéresser au genre. La question est traitée ici du point de vue de la grammaire systémique.

\section{INDEX}

Mots-clés: anglais de spécialité, culture, genre, grammaire

Keywords: culture, ESP, genre, grammar 
AUTHOR

THOMAS MILLER

Thomas Miller works at USIS American Embassy in Paris. MillerT@state.gov 